\title{
Selection of Core for All Steel Sandwich Panel
}

\author{
Anjan Kumar Nandi ${ }^{1}$, Hredey Mishra ${ }^{2}$ \\ ${ }^{1,2}$ Dept. of Mechanical Engineering, JCOE, Kuran, India
}

\begin{abstract}
Sandwich panels can be used for various applications. Many a times aim of the designer is to design panel at which can carry load at min weight and cost. Sandwich panels can be effectively used in such case. Design of facing and core is an important aspect for sandwich panel. Various types of materials like steel, aluminum, composites can be used, among which structural steel is a cost effective material. Various designs are possible for all steel sandwich panel, using various types of core. Standard cores using Zsections, tubular sections, hollow square and rectangular sections, angle sections, $C$-sections, I- sections etc. can be used. Such sections are readily available also produce fairly accurate panel at reasonable cost. Special types of core like corrugated core, honeycomb core can also be used. Generally corrugated \& honeycomb core produce lightest panel but cost of manufacturing will increase substantially. In this paper, we have analyzed all steel sandwich panel having different types of cores using ANSYS. Core size is selected in a manner such that weights of the panel are nearly same this helps in comparison of data. We have analyzed the models in ANSYS for bending load and find out best design among which gives best lowest equivalent stress \& deformation.
\end{abstract}

Keywords: Sandwich Panel, ANSYS, Core Selection, Static Structural

\section{Introduction}

A sandwich panel is consists of two thin, stiff sheets known as skin / facing, joined to either side of a core or structure. Core separates the facings which significantly increase the second moment of area (and hence the bending stiffness) of the cross-section. Core is selected in a manner such that its weight is low.

A wide range of materials can be used for sandwich facings and cores. Common facing materials include metals (e.g. steel or aluminum) and composites (e.g. fiber reinforced polymers).

For all steel sandwich panel, both the sandwich facings and core are metallic materials. The latter can consist of uni- or multi-directional core stiffeners. The normal materials used for all-metal sandwich structures are steel and aluminum. With steel being most common. However when higher weight reduction is required high grade aluminum can be used.

In this paper we have restricted our scope to only all steel sandwich panel. The steel sandwich panels can be constructed with various types of cores as summarized in Fig. 1. The choice of the core depends on the application under consideration. To select best core we need to analyze their performance which can be done using ANSYS.

\section{Type Selection}

Various types of cores that can be used for all steel sandwich panels are shown in Figure. 1. Among those we have selected five types based on literature survey.
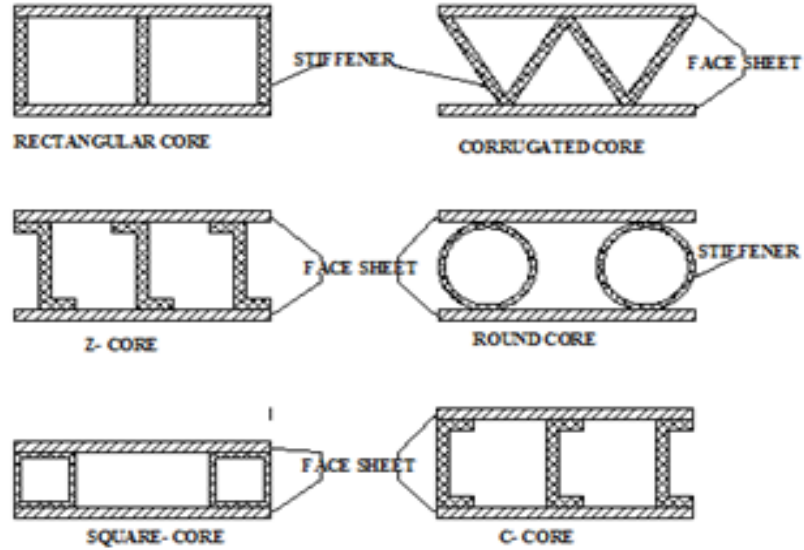

Figure 1: Various types of core stiffeners

These five types have following characteristics:

- Top \& Bottom Facings Steel Plate.

- Core- standard structural steel sections

- Cores and facings are joined by welding

- All materials are Structural Steel

Core sections are selected from standard available structural steel section. This ensures that the materials are readily available. This reduces the cost of production as we do not require any special material also cost of manufacturing reduces under such circumstances.

- Details of the cores are given in Table $-1 \&$ weight of the models are given in Table-2

Table 1: Test piece details

\begin{tabular}{|c|c|c|}
\hline & $\begin{array}{c}\text { Top \& } \\
\text { Bottom } \\
\text { Facing }\end{array}$ & Core Stiffener \\
\hline Model 1 & $\begin{array}{c}3 \mathrm{~mm} \text { th } \\
\text { plate }\end{array}$ & Square tube 19mmSq x 2mm thick Qty 3 nos \\
\hline Model 2 & -do- & C-channel 19mm x9.5mm x 3mm thick Qty 4 nos \\
\hline Model 3 & -do- & Round tube 19mm OD x 3mm thick Qty- 3 nos \\
\hline Model 4 & -do- & Angle 35mm x 35mm x 3mm thick, Qty 3 nos \\
\hline Model 5 & -do- & $\begin{array}{c}\text { Rectangular Plate 19mm height x 3mm thQty } 8 \\
\text { nos }\end{array}$ \\
\hline
\end{tabular}




\section{International Journal of Science and Research (IJSR) \\ ISSN (Online): 2319-7064}

Index Copernicus Value (2015): 78.96 | Impact Factor (2015): 6.391

Table 1: Test piece weights

\begin{tabular}{|c|c|c|}
\hline Model 1 & Square Tube Core & Weight- $6.5 \mathrm{Kg}$ \\
\hline Model 2 & C- Channel core & Weight $-6.5 \mathrm{Kg}$ \\
\hline Model 3 & Round Tube core & Weight $-6.48 \mathrm{Kg}$ \\
\hline Model 4 & Corrugated core & Weight $-7.18 \mathrm{Kg}$ \\
\hline Model 5 & Web core & Weight $-6.5 \mathrm{Kg}$ \\
\hline
\end{tabular}

\section{ANSYS Analysis}

A detailed drawing of models for which ANSYS analysis is done is given in Figure. 2. Most common application is under bending load. Hence, we have carried out static structural analysis under bending load to find out max equivalent stress \& max total deformation which are the acceptance criteria in most of the cases.

\subsection{Material Properties taken for ANSYS analysis:}

Material properties are taken for ANSYS analysis are given in Table 3.

Table 2: Material Properties used for ANSYS Analysis

\begin{tabular}{|c|c|}
\hline Material & Structural Steel \\
\hline Y.S. & $250 \times 10^{6} \mathrm{~N} / \mathrm{m}^{2}$ \\
\hline UTS & $410 \times 10^{6} \mathrm{~N} / \mathrm{m}^{2}$ \\
\hline Compressive & $500 \times 10^{6} \mathrm{~N} / \mathrm{m}^{2}$ \\
\hline Poisson's Ratio & 0.3 \\
\hline Young's Modulus & $2 \times 10^{11} \mathrm{~N} / \mathrm{m}^{2}$ \\
\hline
\end{tabular}

Panel Size: Width- 200mm

Length- $500 \mathrm{~mm}$

Total height- $25 \mathrm{~mm}$

Support: Fixed support on two opposite edges (shorter), other two edges free.

Load- On central plane parallel to shorter edge

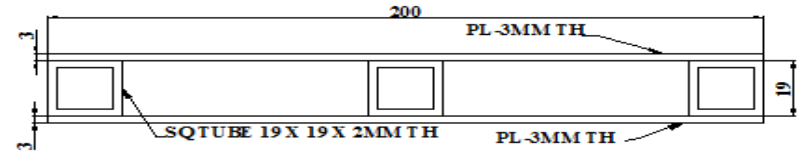

SANDWICH PANEL WITH SQ TUBE STIFFE NER

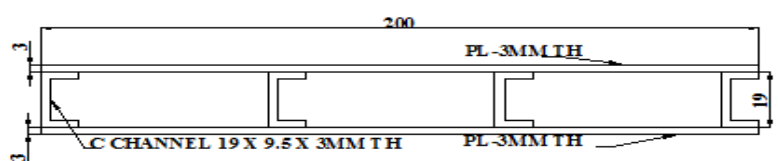

SANDWTCH PANEL WTT H C-CHANNEL STIFFENER

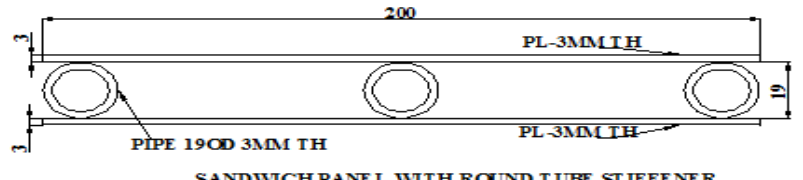

SANDIUTCHPANEL WUTH ROUND T UBE ST IFFENER

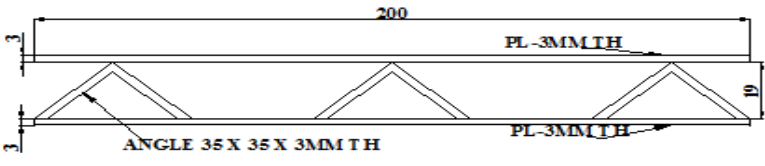

SANDWICH PANEL WITH ANGLE STIFFENE R

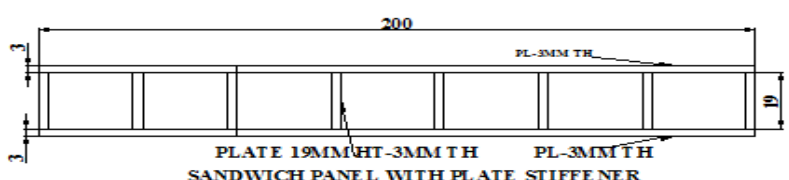

Figure 2Details of model with different cores for ANSYS analysis

\section{Results of ANSYS Analysis}

\subsection{ANSYS result for Square tube core}

ANSYS result for sandwich panel having square tube as core stiffener is given in Table 4.

Table 3: ANSYS result square tube core

\begin{tabular}{|c|c|c|}
\hline Load & Equivalent Stress & Total Deflection \\
\hline$(\mathrm{KN})$ & $(\mathrm{MPa})$ & $(\mathrm{mm})$ \\
\hline 2 & 47.649 & 0.12538 \\
\hline 5 & 119.12 & 0.31346 \\
\hline 8 & 190.6 & 0.50154 \\
\hline 10 & 238.25 & 0.62692 \\
\hline
\end{tabular}

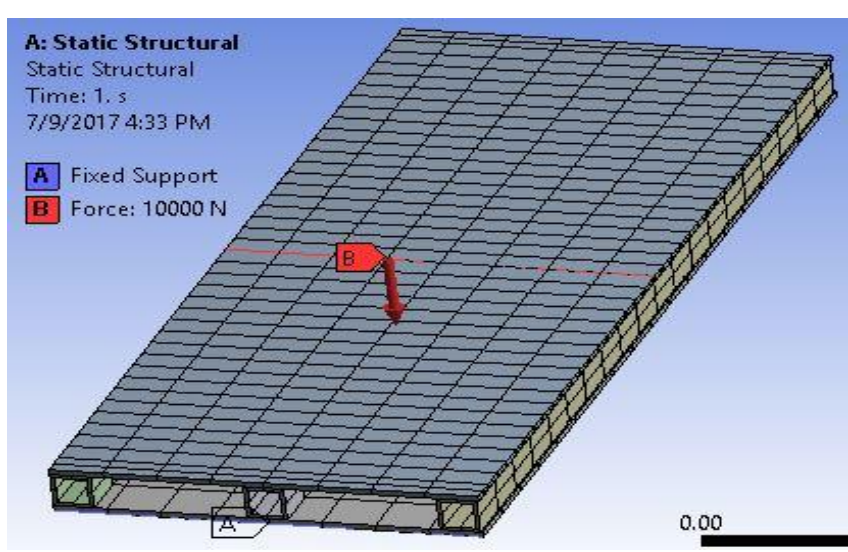

Figure 3: ANSYS model - square tube core

ANSYS model for the above is given in Figure. 3.

\subsection{ANSYS result for C-Channel core}

ANSYS result for sandwich panel having c- channel as core stiffener is given in Table 5.

Table 4: ANSYS result c- channel core

\begin{tabular}{|c|c|c|}
\hline Load & Equivalent Stress & Total Deflection \\
\hline$(\mathrm{KN})$ & $(\mathrm{MPa})$ & $(\mathrm{mm})$ \\
\hline 2 & 36.175 & 0.1099 \\
\hline 5 & 90.439 & 0.27475 \\
\hline 8 & 144.7 & 0.4396 \\
\hline 10 & 180.87 & 0.5495 \\
\hline
\end{tabular}

ANSYS model for the above is given in Figure 4.

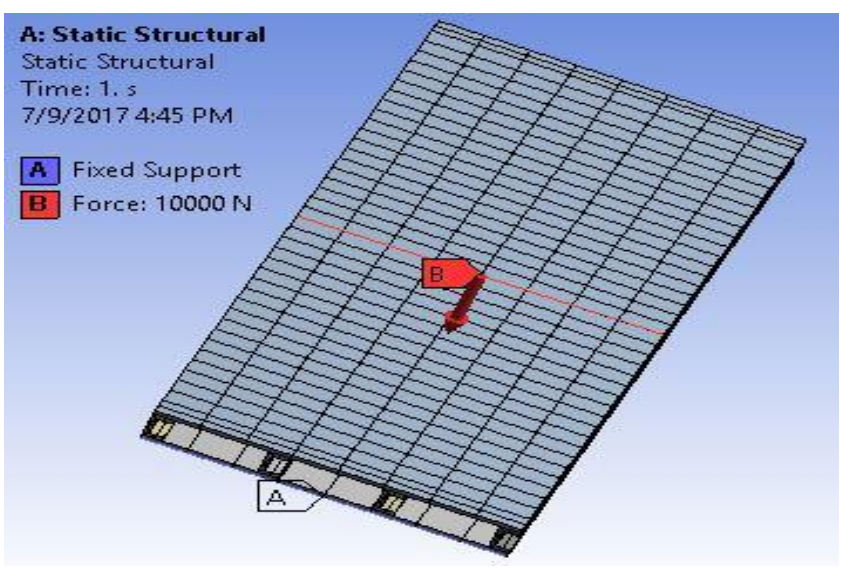

Figure 4: ANSYS model - c-channel core

\section{Volume 6 Issue 7, July 2017 www.ijsr.net}




\section{International Journal of Science and Research (IJSR) \\ ISSN (Online): 2319-7064 \\ Index Copernicus Value (2015): 78.96 | Impact Factor (2015): 6.391}

\subsection{ANSYS result for round tube core:}

ANSYS result for sandwich panel having round tube as core stiffener is given in Table 6

Table 5: ANSYS result round tube core

\begin{tabular}{|c|c|c|}
\hline Load & Equivalent Stress & Total Deflection \\
\hline$(K N)$ & $(M P a)$ & $(\mathrm{mm})$ \\
\hline 2 & 52.639 & 0.12882 \\
\hline 5 & 131.6 & 0.32205 \\
\hline 8 & 210.55 & 0.51528 \\
\hline 10 & 263.19 & 0.6441 \\
\hline
\end{tabular}

ANSYS model for the above is given in Figure 5.

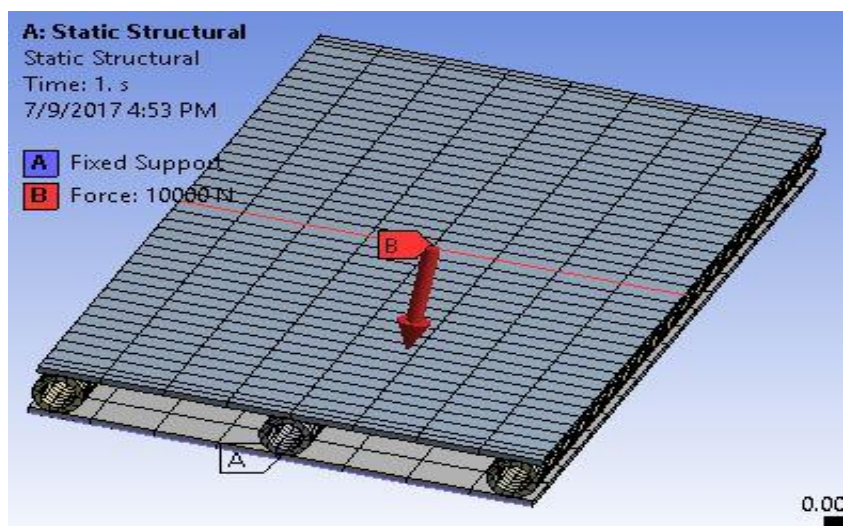

Figure 5: ANSYS model - round tube core

\subsection{ANSYS result for angle core:}

ANSYS result for sandwich panel having angle as core stiffener is given in Table 7

Table 6: ANSYS result angle core

\begin{tabular}{|c|c|c|}
\hline Load & Equivalent Stress & Total Deflection \\
\hline$(\mathrm{KN})$ & $(\mathrm{MPa})$ & $(\mathrm{mm})$ \\
\hline 2 & 37.012 & 0.11116 \\
\hline 5 & 92.53 & 0.2779 \\
\hline 8 & 148.05 & 0.44464 \\
\hline 10 & 185.06 & 0.5558 \\
\hline
\end{tabular}

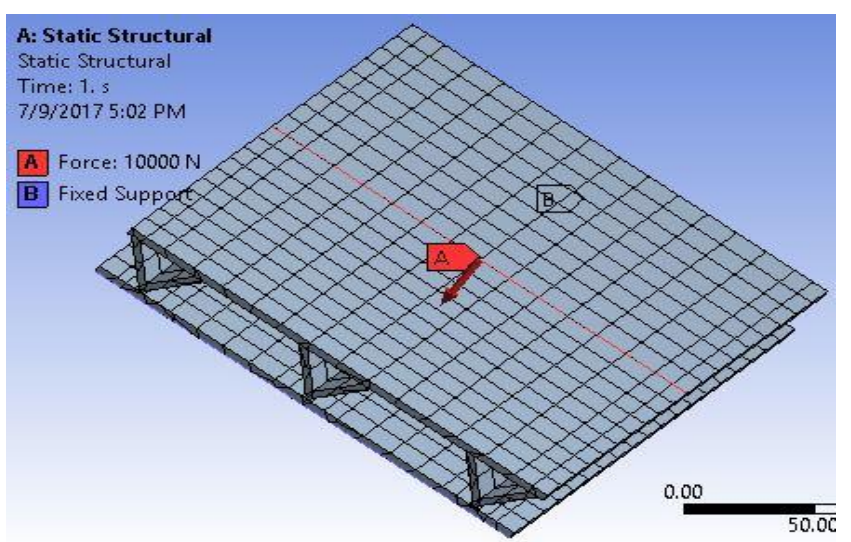

Figure 6ANSYS model - angle core
ANSYS model for the above is given in Figure 6

\subsection{ANSYS result for rectangular plate core}

ANSYS result for sandwich panel having rectangular plate as core stiffener is given in Table 8 .

Table 7: ANSYS result rectangular plate core

\begin{tabular}{|c|c|c|}
\hline Load & Equivalent Stress & Total Deflection \\
\hline$(\mathrm{KN})$ & $(\mathrm{MPa})$ & $(\mathrm{mm})$ \\
\hline 2 & 41.278 & 0.098039 \\
\hline 5 & 103.2 & 0.2451 \\
\hline 8 & 165.11 & 0.39875 \\
\hline 10 & 206.39 & 0.49019 \\
\hline
\end{tabular}

ANSYS model for the above is given in Figure 7.

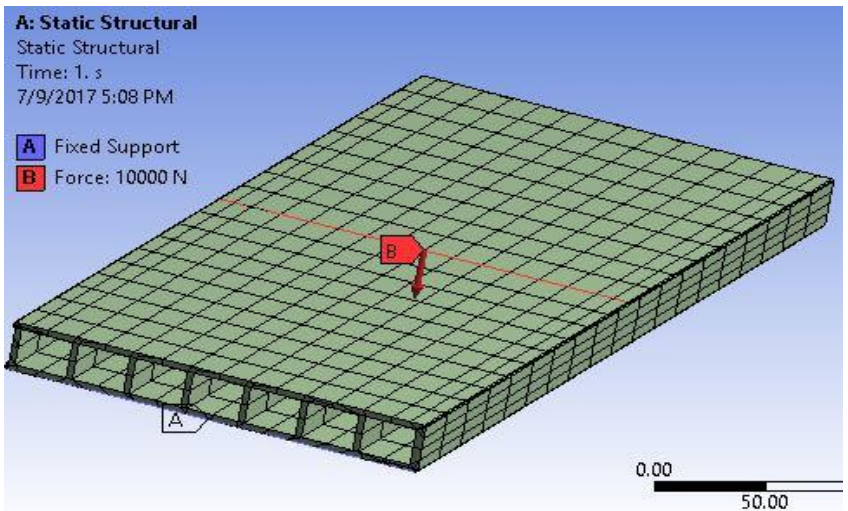

Figure 7: ANSYS model rectangular plate core

\section{Conclusion}

Comparison of Equivalent stress for various stiffeners is given in Figure 8.

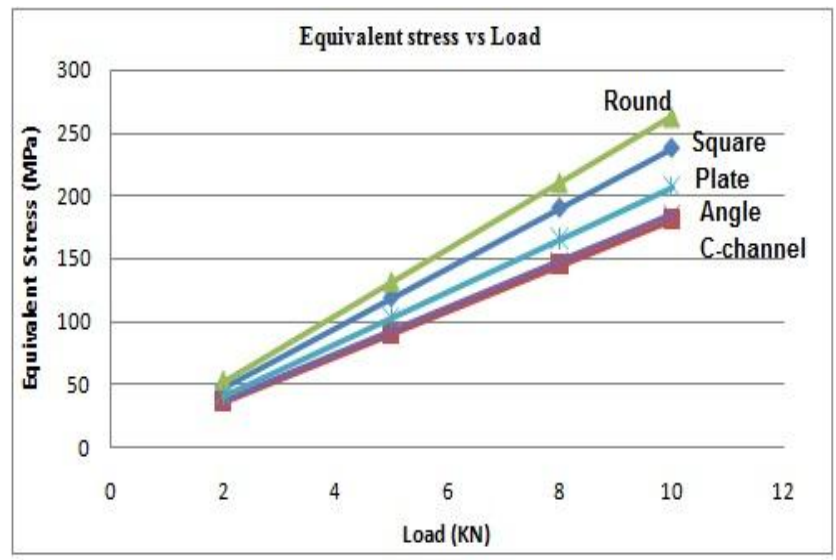

Figure 8: Variation of equivalent stress

Comparison of Equivalent stress for various stiffeners is given in Figure 9. 


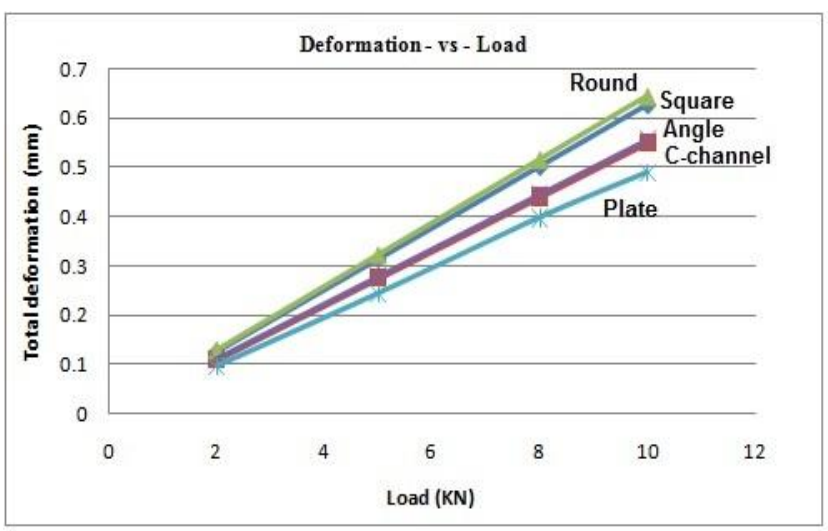

Figure 9: Variation of total deformation

From the above comparison it is observed that c-channel gives list equivalent stress \& rectangular plate gives least deformation.

Depending upon the application and design criteria either equivalent stress or deformation may be the limiting criteria. Based on the same we can select the core best suitable for our purpose.

\section{References}

[1] Alen Howard G ,Analysis and Design of structural Sandwich Panels, Pergamon Press, London, 1969, pp02 to 13

[2] JukkaSäynäjäkangas and TeroTaulavuori, Outokumpu "A Review in Design and Manufacturing of Stainless Steel Sandwich Panels" Stainless Oy, Finland, sandwi 2004 Page 21-24

[3] Bagadi, Gopi Krishna; B. Rambabu, "Design and Analysis of Stainless Steel and Mild Steel Sandwich Composite Structure",IJMETMR Vol-2, April 2015, pp-624-632

[4] Devendra B. Sonawane, Prof. R. N. Garad, Pratik K. Satav,"Composite Section Design for Minimum Weight in Structural Application",IJSR, 2013 pp. 1469-147

\section{Author Profile}

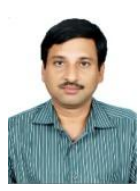

Anjan Kumar Nandi received the B.E. degrees in Mechanical Engineering from RE college Durgapur in 1994, and presently doing ME in Mechanical Design Engineering from JCOE Kuran, Pune University.

anjannandi@hotmail.com

Hredey Mishra: Prof JCOE Kuran

hredeyamishra@gmail.com 